\title{
The supposed tumor suppressor gene WWOX is mutated in an early lethal microcephaly syndrome with epilepsy, growth retardation and retinal degeneration
}

Ghada Abdel-Salam ${ }^{1}$, Michaela Thoenes ${ }^{2}$, Hanan H Afifi ${ }^{1}$, Friederike Körber ${ }^{3}$, Daniel Swan ${ }^{4}$ and Hanno Jörn Bolz ${ }^{2,5^{*}}$

\begin{abstract}
Background: WWOX, encoding WW domain-containing oxidoreductase, spans FRA16D, the second most common chromosomal fragile site frequently altered in cancers. It is therefore considered a tumor suppressor gene, but its direct implication in cancerogenesis remains controversial.

Methods and results: By whole-exome sequencing, we identified a homozygous WWOX nonsense mutation, p.Arg54*, in a girl from a consanguineous family with a severe syndrome of growth retardation, microcephaly, epileptic seizures, retinopathy and early death, a phenotype highly similar to the abormalities reported in Ide/lde rats with a spontaneous functional null mutation of Wwox. As in rats, no tumors were observed in the patient or heterozygous mutation carriers.
\end{abstract}

Conclusions: Our finding, a homozygous loss-of-function germline mutation in WWOX in a patient with a lethal autosomal recessive syndrome, supports an alternative role of WWOX and indicates its importance for human viability.

Keywords: WWOX, Tumor suppressor gene, Microcephaly, Epilepsy, Retinal degeneration, Nonsense mutation, Whole-exome sequencing

\section{Background}

WWOX has been extensively studied for its role in cancer because it localizes to a common fragile site, FRA16D, a genomic region susceptible to chromosomal rearrangements [1]. Indeed, somatic homozygous $W W O X$ deletions are common in various malignancies. Early lethality in mice with targeted Wwox ablation has largely prevented studies on tumor susceptibility, although focal bone lesions were interpreted as early osteosarcomas. Spontaneous tumor incidence was elevated in heterozygous mice, and exposure to chemical mutagens further promoted tumor formation [2]. Some studies in mice with conditional Wwox deletion, however, did not support the categorization of $W W O X$ as a primary tumor suppressor

\footnotetext{
* Correspondence: hanno.bolz@uk-koeln.de

${ }^{2}$ Institute of Human Genetics, University Hospital of Cologne, Cologne, Germany

${ }^{5}$ Center for Human Genetics, Bioscientia, Ingelheim, Germany

Full list of author information is available at the end of the article
}

gene since no spontaneous neoplasms were observed $[3,4]$. Recently, expression studies in mice and the phenotype of rats with homozygosity for a spontaneous loss-offunction allele have drawn the attention to a possible role of $W W O X$ in the developing central nervous system, including the retina [5-7].

\section{Methods \\ Patients}

We have evaluated five members of a consanguineous Egyptian family. Written informed consent was obtained from the parents, and the study was approved by the institutional review board of the Ethics Committee of the University Hospital of Cologne and by the Ethics Committee of the National Research Centre, Cairo.

\section{Genetic investigations}

Genomic DNA of II:4 was subjected to whole-exome sequencing, WES. Exome capture was performed using 
the Agilent SureSelectXT Human All Exon $50 \mathrm{Mb}$ kit following manufacturer's procedures (Agilent, Santa Clara, CA, USA) and sequenced with Illumina paired end sequencing (protocol v1.2). Briefly, DNA was sheared by fragmentation (Covaris, Woburn, MA, USA) and purified using Agencourt AMPure XP beads (Beckman Coulter, Fullerton, CA, USA). Resulting fragments were analysed using an Agilent 2100 Bioanalyzer. Fragment ends were repaired and adaptors were ligated to the fragments. The library was purified using Agencourt AMPure XP beads and amplified by PCR before hybridisation with biotinylated RNA baits. Bound genomic DNA was purified with streptavidin coated magnetic Dynabeads (Invitrogen, Carlsbad, CA, USA) and reamplified to include barcoding tags before pooling for sequencing on an paired-end, 100 cycle run on an Illumina HiSeq 2000 according to manufacturer's protocols. Exome analysis was completed in OGT's exome pipeline. Briefly, reads were aligned to the human genome reference sequence GRCh37 using bwa 0.6.2. [8]. Local realignment was performed around indels with the Genome Analysis Toolkit (GATK v1.6) IndelRealigner [9]. Optical and PCR duplicates were marked in BAM files using Picard 1.83 (http://picard.sourceforge.net).
Original HiSeq base quality scores were recalibrated using GATK TableRecalibration and variants called with GATK UnifiedGenotyper. Indels and SNPs were hard-filtered according to Broad Institute best-practice guidelines (http:// www.broadinstitute.org/gatk/guide/topic?name=bestpractices) to eliminate false positive calls. Variant annotation was done with a modified version of ENSEMBL's Variant Effect Predictor. 14,268,914 read pairs were generated of which $98.96 \%$ aligned to the human reference sequence [10]. $85 \%$ of sequenced bases were characterized as 'on bait' or 'near bait'. The sample was sequenced to a mean target coverage of $33.4 \times$, with $64 \%$ of bases sequenced to a depth of $20 \times$ or more.

\section{Results}

We have evaluated five members of a consanguineous Egyptian family (the healthy parents were $2^{\text {nd }}$-degree cousins) with the index patient, II:4 (Table 1 and Figure 1A,B), affected by a novel syndrome with neonatal growth retardation, microcephaly, retinal dystrophy, severe psychomotor delay and intractable epileptic seizures. She was born at 38 weeks by cesarean section as $2^{\text {nd }}$ twin after an uncomplicated pregnancy. Birth weight of II:4 was 2,000 g (below P3). Birth length and head

Table 1 Comparison of clinical findings in patient II:4, in the spontaneous rat mutant [7] and in knockout mice [20-22]

\begin{tabular}{|c|c|c|c|c|c|c|c|c|c|}
\hline & wWOX & $\mathrm{MCPH}$ & Retinopathy & Stature & Seizures & $\begin{array}{l}\text { Brain } \\
\text { abnormalities }\end{array}$ & $\begin{array}{l}\text { Dev. } \\
\text { delay }\end{array}$ & $\begin{array}{l}\text { Blood count, } \\
\text { metabolism }\end{array}$ & Death \\
\hline \multirow[t]{7}{*}{ II:4 } & \multirow[t]{7}{*}{$\begin{array}{l}\text { p.Arg54* } \\
\text { homozygous }\end{array}$} & \multirow[t]{7}{*}{+} & \multirow[t]{7}{*}{$\begin{array}{l}\text { RP, optic } \\
\text { atrophy }\end{array}$} & \multirow[t]{7}{*}{$\begin{array}{l}\text { Short, growth } \\
\text { retardation }\end{array}$} & \multirow[t]{7}{*}{+} & $\begin{array}{l}\text { - Supratentorial } \\
\text { atrophy }\end{array}$ & \multirow[t]{7}{*}{+} & $\begin{array}{l}\text { - No metabolic } \\
\text { disorder }\end{array}$ & \multirow[t]{7}{*}{$16 \mathrm{mo}$} \\
\hline & & & & & & $\begin{array}{l}\text { - Centr/cortical } \\
\text { atrophy }\end{array}$ & & $\begin{array}{l}\text { - Normal blood } \\
\text { count }\end{array}$ & \\
\hline & & & & & & - Hypoplasia of CC & & \multirow[t]{5}{*}{ - No tumors } & \\
\hline & & & & & & - Hippocamp. dysplasia & & & \\
\hline & & & & & & $\begin{array}{l}\text { - Temporal lobe } \\
\text { hypotrophy }\end{array}$ & & & \\
\hline & & & & & & $\begin{array}{r}\text { - Hippocampal } \\
\text { malformation }\end{array}$ & & & \\
\hline & & & & & & - Gyral pattern anomaly & & & \\
\hline \multirow[t]{4}{*}{ Rat } & \multirow{4}{*}{$\begin{array}{l}\text { p.Leu371Thrfs*41 } \\
\text { homozygous } \\
\text { (functional } \\
\text { null, no protein } \\
\text { produced) }\end{array}$} & \multirow[t]{4}{*}{ n.d. } & \multirow[t]{4}{*}{ n.d. } & \multirow[t]{4}{*}{ Dwarfism } & \multirow[t]{4}{*}{+} & \multirow{4}{*}{$\begin{array}{l}\text { Extracellular vacuoles } \\
\text { (hippocampus, amygdala) }\end{array}$} & \multirow[t]{4}{*}{+} & - Hypogonadism ${ }^{1}$ & \multirow[t]{4}{*}{ 3-12 weeks } \\
\hline & & & & & & & & $\begin{array}{l}\text { - No metabolic } \\
\text { disorder }\end{array}$ & \\
\hline & & & & & & & & $\begin{array}{l}\text { - Bone metabolic } \\
\text { disease (mild) }\end{array}$ & \\
\hline & & & & & & & & - No tumors & \\
\hline \multirow[t]{4}{*}{ Mouse } & \multirow{4}{*}{$\begin{array}{l}\text { Homozygous } \\
\text { knockout }\end{array}$} & \multirow[t]{4}{*}{ n.d. } & \multirow[t]{4}{*}{ n.d. } & \multirow[t]{4}{*}{ Dwarfism } & \multirow[t]{4}{*}{ no } & \multirow[t]{4}{*}{ n.d. } & \multirow[t]{4}{*}{+} & - Hypogonadism ${ }^{2}$ & \multirow[t]{4}{*}{ 2-3 weeks } \\
\hline & & & & & & & & $\begin{array}{l}\text { - Metabolic } \\
\text { disorder }^{3}\end{array}$ & \\
\hline & & & & & & & & $\begin{array}{l}\text { - Bone metabolic } \\
\text { disease (severe) }\end{array}$ & \\
\hline & & & & & & & & - Osteosarcoma ${ }^{4}$ & \\
\hline
\end{tabular}

'Leydig cell dysfunction, apoptosis of spermatocytes, low FSH and LH (prepubertal), low testosterone; ${ }^{2}$ Failure of Leydig cell development; ${ }^{3} \mathrm{Hypoproteinemia,}$ hypoglycemia, hypocalcemia, hypotriglyceridemia, hypocholesterolemia, hyponatremia, hyperkalemia, hypochloremia; ${ }^{4}$ Increased susceptibility to develop malignancies was not supported by other studies on Wwox-deficient mice (see Discussion). 


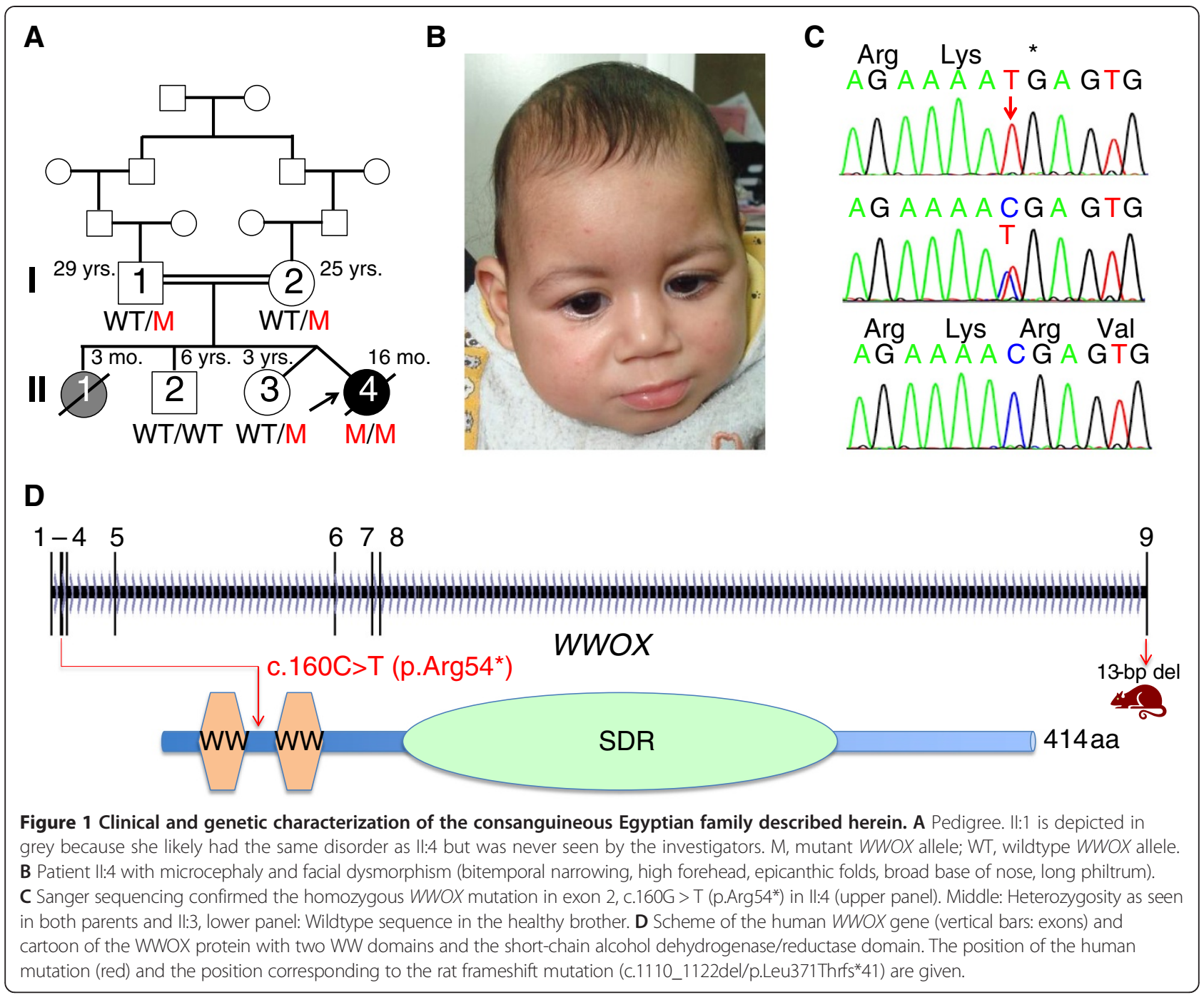

circumference were not documented, but at 3 months of age weight was $4,200 \mathrm{~g}(-2.1 \mathrm{SD})$, length $53 \mathrm{~cm}(-2.3 \mathrm{SD})$ and head circumference (OFC) $34 \mathrm{~cm}$ (-3.6 SD). At 12 months, her weight was $5,800 \mathrm{~g}(-3.6 \mathrm{SD})$, length $66 \mathrm{~cm}$ (-2.9 SD) and OFC $39 \mathrm{~cm}$ (-4.6 SD). She had bitemporal narrowing, a high forehead, blue sclerae, epicanthic folds, anteverted nares, a long philtrum, a short neck, and clenched hands. Convulsions started at the age of 2 months. At 12 months, seizures started as hemiconvulsions with abnormal eye and mouth movements. Myoclonic movements persisted. Seizures partially responded to valproate and lamotrigine. Deep tendon reflexes of upper and lower extremities and flexor plantar responses were increased. II:4 did not acquire any developmental milestones and never recognized her mother. There were no vocalizations. EEG showed generalized epileptic abnormalities with frequent bursts of sharp and slow waves. Parents noticed lack of response to any visual stimuli at the age of two months, and ophthalmological examination revealed optic atrophy with abnormal retinal pigmentation. Scotopic and photopic flash electroretinogram (ERG) showed moderately reduced response indicating retinal dysfunction. Photopic flicker ERG revealed markedly reduced responses. Visual evoked potential (VEP) showed reduced wave amplitudes and great implicit time delays. In summary, the ophthalmological examination indicated major impairment of retinocortical transmission indicative for delayed visual maturation, and bilateral severe macular and optic nerve dysfunction. Echocardiography and audiological evaluation were normal. Cranial MRI demonstrated supratentorial atrophy with simplified gyral pattern, hypoplasia of the hippocampus and the temporal lobe with consecutively widened subarachnoidal space, and a thin hypoplastic corpus callosum. Chromosomal examination from peripheral blood lymphocytes revealed a normal female karyotype, 46,XX. Normal results were found in metabolic screening including liver and renal function tests, complete blood count, 
blood gas analyses, ammonia, serum lactate, plasma urea, electrolytes, urine and serum amino and organic acids, and very long chain fatty acids. II:4 died at the age of 16 months because of status epilepticus. No autopsy was performed.

The $1^{\text {st }}$ twin of II:4, II:3, was a healthy girl. The older sister of II:4, patient II:1, deceased at 3 months of age with similar symptoms, probably affected by the same, presumably recessive disorder. Patient II:1 died several years ago and has not been seen by the authors because the family was only referred to genetic counseling after II:4 had been born with similar symptoms. II:1 was born as first child at 39 weeks of gestation by spontaneous vaginal delivery after an uncomplicated pregnancy. The father and mother were 22 and 26 years old then, respectively. Records on neonatal growth parameters were not available. Seizures started at the age of 40 days as generalized tonic-clonic fits that could partially be controled by valproate and lamotrigine. At 2 months of age, the parents noticed that she was not following objects and did not react to light. No detailed ophthalmological investigations or brain imaging were done. At 3 months, she was admitted to hospital because of heavy convulsions and died one week later during sleep. Autopsy was not performed. There were no additional individuals in the family with symptoms comparable to those of II:1 and II:4. There was no history of cancer, not even in the older generations.

WES identified 41,639 SNPs and indel variant positions, of which 2,597 had not been previously identified in dbSNP release 132. 495 of these were nonsynonymous. To reduce the search space for causative mutations, the 41,693 variants were filtered stringently, removing variants that had been seen in OGT's private database in $30 \%$ or more of previously analysed samples. Variants were also removed if they were present in dbSNP release 137 or had been identified as part of the 1000 Genomes project. After this filtering 639 variants (of all consequences) remained. Reducing variants to only exonic regions left 523 novel variants. Assuming that the disease-causing mutation locates in a region of homozygosity by descent (HBD) [11], variants were filtered for homozygous positions. Considering only those variants with a "serious" tag in the OGT pipeline (affecting essential splice sites; frameshifts in coding sequence; gained or lost stop codons; non-synonymous coding variants; complex insertions/deletions) further reduced them to 15 (Table 2). LOH (loss of heterozygosity) regions, probably reflecting HBD segments resulting from parental consanguinity, were identified by analysing the regions surrounding candidate variants in the VCF file, excluding sites with low coverage, known polymorphic genes and potentially mis-genotyped homopolymer indels to define the region sizes presented in Table 2.
Only five variants were predicted as deleterious by all or most programs and localized to $\mathrm{LOH}$ regions, including a gained stop codon in WWOX (WW domain containing oxidoreductase) that localizes in exon 2 and affects codon 54 for arginine (c.160G > T; p.Arg54*) in the largest $\mathrm{LOH}$ region identified $(54 \mathrm{Mb})$ (chr16:25,457,30579,894,309; GRCh37) [Additional file 1: Figure S1]. It is homozygous for SNPs with the exception of PDPR, a gene exhibiting common copy-number polymorphism. Sanger sequencing confirmed the homozygous WWOX mutation in II:4, and both parents and the healthy twin sister (II:3) were heterozygous carriers. The healthy brother (II:2) was homozygous for the wildtype allele (Figure 1C). There are no variants at this position (c.160) of WWOX in the Exome Variant Server database. There are some rare missense variants (with minor allele frequencies $<1 \%$ ), but only two other stop gain mutations, c.214C > T (p.Gln72*; rs201008667) and c.749C > G (p.Ser250*; rs368928190). A gained stop codon in POMC (proopiomelanocortin) had been sequenced at very low depth $(3 \times)$ in WES and turned out heterozygous by Sanger sequencing.

\section{Discussion}

Many genes have been assigned roles in tumorigenesis at the time of their discovery based on expression studies, somatic alterations in tumor cells or both. For example, FUS (fused in sarcoma) was initially classified as a fusion oncogene in human myxoid liposarcomas [12], and later implicated in Mendelian neurodegeneration through the identification of germline mutations in familial amyotrophic lateral sclerosis [13]. Another example is the unexpected identification of germline mutations in members of the Ras signaling pathway in different monogenic syndromes, including a neurodevelopmental disorder, Costello syndrome [14]. Similarly, we have identified a homozygous truncating germline mutation in $W W O X$, a gene so far considered a tumor suppressor gene, in a severe recessive neurodevelopmental syndrome.

The implication of $W W O X$ in a monogenic disorder may appear unexpected. However, the probability of WWOX being a recessive disease gene ranked very high (31) in an estimation for 14,142 genes [15]. This is compatible with only two other stop gain mutations of very low frequency, p.Gln72\% (MAF 0.016\%) and p.Ser250* (MAF 0.008\%), listed in the Exome Variant Server database, likely representing rare pathogenic recessive alleles. Moreover, there is considerable overlap of symptoms in our patients with those observed in Wwox murine models (Table 1): A spontaneous homozygous Wwox frameshift mutation (p.Leu371Thrfs*41) resulting in non-detectable protein underlies lethal dwarfism and epilepsy (lde) in lde/lde rats, suggesting an important 
Table 2 Apparently homozygous variants in WES data of II:4 remaining after stringent filtering (see Results)

\begin{tabular}{|c|c|c|c|c|c|c|c|c|c|c|c|c|}
\hline Gene & Chr & $\begin{array}{l}\text { Position } \\
\text { (hg19) }\end{array}$ & Depth & $\begin{array}{l}\text { Nucleotide } \\
\text { alteration }\end{array}$ & Protein alteration & Sift & Polyphen & Condel & Mutation taster & $\begin{array}{l}\text { Known Mendelian } \\
\text { disease gene }\end{array}$ & $\begin{array}{l}\text { Cosegreg. } \\
\text { with disease }\end{array}$ & $\begin{array}{l}\mathrm{LOH} \\
\text { region }(\mathrm{Mb})\end{array}$ \\
\hline POMC & 2 & 25384251 & 3 & c. $503 C>A$ & p. Ser168* & n.a. & n.a. & n.a. & delet & $\begin{array}{l}\text { Early-onset obesity, } \\
\text { adrenal insufficiency, } \\
\text { red hair; ar }\end{array}$ & no & no \\
\hline IMPG2 & 3 & 100995556 & 13 & c. $535 \mathrm{~T}>\mathrm{G}$ & $\begin{array}{l}\text { p. Ser179Ala (intronic } \\
\text { in most transcripts!) }\end{array}$ & tol & tol & tol & tol & Recessive retinitis, ar & n.d. & 20 \\
\hline PHACTR1 & 6 & 12749777 & 4 & delC & - & n.a. & n.a. & n.a. & & no & n.d. & no \\
\hline TAS2R38 & 7 & 141672688 & 34 & c. $802 C>T$ & p. Pro268Ser & tol & delet & delet & tol & no & n.d. & 2.2 \\
\hline ERMP1 & 9 & 5832849 & 3 & c. $179 \mathrm{C}>\mathrm{T}$ & p. Ala60Val & tol & tol & tol & tol & no & n.d. & 3 \\
\hline MRRF & 9 & 125033286 & 112 & c. $116 \mathrm{~A}>\mathrm{G}$ & p. His39Arg & tol & tol & tol & tol & no & n.d. & 2.7 \\
\hline GLE1 & 9 & 131302562 & 18 & c. $1211 C>T$ & p. Ala404Val & tol & delet & delet & delet & $\begin{array}{l}\text { Lethal arthrogryposis } \\
\text { with anterior horn cell } \\
\text { disease, ar }\end{array}$ & n.d. & 3.7 \\
\hline HCFC2 & 12 & 104461873 & 60 & c. $461 \mathrm{~A}>\mathrm{T}$ & p. Asn154lle & delet & delet & delet & delet & no & n.d. & 3.3 \\
\hline RBM19 & 12 & 114261045 & 18 & c. $2867 \mathrm{~A}>\mathrm{C}$ & p. Gln956Pro & delet & tol & tol & tol & no & n.d. & 3.6 \\
\hline SPTBN5 & 15 & 42174192 & 8 & c. 2392_2393ins & p. Glu800Glyfs*41 & n.a. & n.a. & n.a. & delet & no; LoF-tolerant gene! & no & no \\
\hline DUS2L & 16 & 68107968 & 14 & c. $842 C>G$ & p. Thr281Ser & tol & tol & tol & delet & no & n.d. & 38 \\
\hline AP1G1 & 16 & 71784192 & 70 & c. $1328 \mathrm{~A}>\mathrm{T}$ & p. Gln443Leu & tol & tol & tol & delet & no & n.d. & 1.8 \\
\hline ZFHX3 & 16 & 72821594 & 76 & c. 10804_10812del & p. Ala3602_Ala3604del & n.a. & n.a. & n.a. & tol & no & n.d. & 8.6 \\
\hline wWox & 16 & 78142372 & 12 & c. $160 \mathrm{G}>\mathrm{T}$ & p. $\operatorname{Arg} 54^{*}$ & n.a. & n.a. & n.a. & delet & no & yes & 54 \\
\hline$A B C G 1$ & 21 & 43680243 & 3 & c. $718 \mathrm{G}>\mathrm{A}$ & p. Glu240Lys & tol & tol & tol & tol & no & n.d. & no \\
\hline
\end{tabular}

Variants in TAS2R38, GLE1, HCFC2, ZFHX3 and WWOX represented prime candidate variants because they localized within an LOH region and were predicted as pathogenic by most programs. Note that the POMC nonsense mutation was covered only 3 times, and Sanger sequencing revealed that it was in fact heterozygous which is compatible with POMC not localizing in an LOH region. The SPTBN5 frameshift mutation was found to be homozygous in II:4 and her healthy twin. SPTBN5 has been described as a non-essential gene that tolerates loss-of-function variants (LoF-tolerant) [15]. ar, autosomal recessive; n.a., not applicable: Assessment of deletions or insertions is out of scope for the methods of the prediction programs which require knowledge of the ancestral amino acids at that position (except Mutation Taster); delet, predicted as deleterious; tol, predicted as being tolerated; n.d., not defined: Segregation analysis was not carried out; LOH region: If a variant is embedded in a run of homozygous SNPs, indicating a loss of heterozygosity region, the extent of this region is given in $\mathrm{Mb}$, megabases. 
role of $W W O X$ for development and integrity of the nervous system [7]. lde/lde rats display vacuoles in the hippocampus, a brain region that appeared dysplastic in the MRI of patient II:4 (Figure 2A). Like patient II:4 and lde/lde rats, knockout mice show growth retardation and die early, but no seizures were observed.

Wwox is highly expressed in different brain regions during murine fetal development. Whilst mostly decreasing after birth it remained unchanged in the cortex and the corpus callosum in adult mice [6] - which fits the observation of cortical atrophy and hypoplasia of the corpus callosum in our patients. The intractable epileptic seizures observed in the human family and in the rat model will at least in part result from these anatomical brain abnormalities, but considering the putative role of WWOX as a signaling protein [16], disruption of neuronal pathways may additionally increase the susceptibility for seizures.

Severe retinal degeneration and optic atrophy were present in II:4 and probably in II:1, too, and compatible with early infantile retinitis pigmentosa, RP. Interestingly, Wwox is moderately to highly expressed in the murine developing retina [6] and overexpressed in the inner and outer nuclear layers after light-induced damage [5]. It colocalizes with opsin-positive cones and was enriched in damaged mitochondria and condensed nuclei of degenerating photoreceptors [5]. Intriguingly, Wwox was upregulated with age in retinae of $r d$ mice with mutations in Pde6b, a recessive RP gene in humans [17]. In monogenic forms of optic atrophy, the disease primarily affects the retinal ganglion cells (RGCs) [18]. The specific expression of Wwox in RGCs, its colocalization with Brn3b [6], a protein that is crucial for RGC axon outgrowth [19], and continued expression in the optic tract in adulthood could explain the optic atrophy in our patients.

By interaction with many proteins via its WW and SDR domains, WWOX is thought to act in various signaling pathways $[2,16]$. In $W W O X$ deficiency, disease in the central nervous system may result from disruption of some of these interactions, e.g. with dishevelled segment polarity protein 2 (DVL2) and Tau, proteins involved in cortical development and neurodegeneration [2]. The severe dwarfism in $W w o x^{-1-}$ mice has been attributed to delayed bone formation resulting from dysregulation of RUNX2, a WWOX-controlled regulator of skeletal morphogenesis, and to down-regulation of genes for nucleosome assembly and cell growth [20].

Metabolic disease has been reported in Wwox-deficient mice (see legend for Table 1), but was not evident during her short life in patient II:4. Spontaneous tumor incidence was moderately elevated in heterozygous Wwox knockout mice compared to wildtype, and exposure to chemical mutagens dramatically promoted tumor formation [21]. However, some mouse studies raised doubts on the gene's role as a classical tumor suppressor [3,4,20-22], and neither the rat model nor members from the human family reported here displayed a tendency to develop tumors. It is possible that tumors would have developed later in life in II:1 and II:4 if the condition would have been compatible with a longer survival. No tumors have developed so far in the heterozygous carriers in our family, and there was no history for cancer in the extended family (with possibly several carriers of the mutation). However, an increased cumulative lifetime risk, especially if exposed to carcinogenic agents, seems conceivable and should result in regular preventive medical checkups.
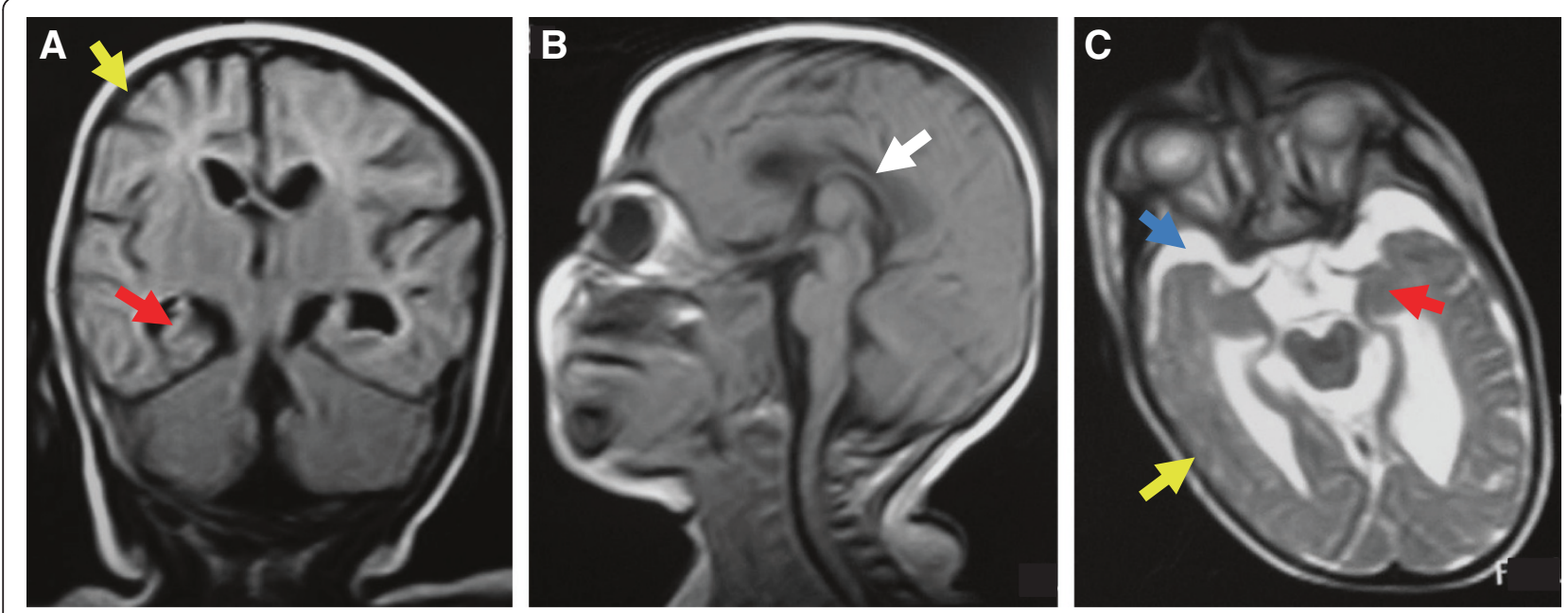

Figure 2 Brain MRIs of II:4. A Supratentorial atrophy with thin cerebral cortex (yellow arrow) and hippocampal dysplasia (red arrow) are visible in the coronal plane. B Hypoplasia of corpus callosum. Note craniofacial dysproportion and sloping forehead (sagittal MRI). $\mathbf{C}$ Hypotrophic temporal lobes with widened subarachnoidal space (blue arrow), hippocampal malformation (red arrow) and gyral pattern anomaly (axial MRI). 


\section{Conclusions}

Our findings - albeit based on the presumption that the causative mutation in this consanguineous family will be homozygous (we can not exclude disease-causing compound heterozygosity in a gene outside the HBD regions) - suggest a redefinition of WWOX as a protein that has entirely different functions in the germline versus the soma. It joins the ranks of other tumor suppressor genes that have been recognized to be crucial for neurodevelopment when mutated in the germline.

\section{Additional file}

Additional file 1: Figure $\mathbf{S 1}$. Schematic representation of the mapped sequencing reads covering the WWOX mutation in patient II:4 (visualized with the Integrative Genomics Viewer, IGV)

\section{Competing interests}

$\mathrm{HJB}$ is employee of Bioscientia which is part of a publicly traded diagnostic company. The other authors have no competing interests.

\section{Authors' contributions}

GAS, HHA and FK carried out the clinical characterization of the family. MT carried out the molecular genetic studies apart from exome sequencing. DS performed exome sequencing and bioinformatic/statistical analysis. GAS and HJB designed the study. HJB wrote the manuscript. All authors read and approved the final manuscript.

\section{Acknowledgment}

We are indebted to the family who participated in this study. We thank Dr. Raoul Heller for critical reading and very helpful discussions. The study was supported by the Marie-Louise Geissler-Stiftung and by the Imhoff-Stiftung (to HJB).

\section{Author details}

${ }^{1}$ Department of Clinical Genetics, National Research Centre, Cairo, Egypt ${ }^{2}$ Institute of Human Genetics, University Hospital of Cologne, Cologne, Germany. ${ }^{3}$ Department of Radiology, University of Cologne, Cologne, Germany. ${ }^{4}$ Computational Biology Group, Oxford Gene Technology, Oxford, OX5 1PF, UK. ${ }^{5}$ Center for Human Genetics, Bioscientia, Ingelheim, Germany.

Received: 25 September 2013 Accepted: 22 January 2014

Published: 23 January 2014

\section{References}

1. Dayan S, O'Keefe LV, Choo A, Richards Rl: Common chromosomal fragile site FRA16D tumor suppressor WWOX gene expression and metabolic reprograming in cells. Genes Chromosomes Cancer 2013, 52:823-831.

2. Del Mare S, Salah Z, Aqeilan RI: WWOX: its genomics, partners, and functions. J Cell Biochem 2009, 108:737-745.

3. Ferguson BW, Gao X, Kil H, Lee J, Benavides F, Abba MC, Aldaz CM: Conditional Wwox deletion in mouse mammary gland by means of two Cre recombinase approaches. PLoS One 2012, 7:e36618.

4. Ludes-Meyers JH, Kil H, Parker-Thornburg J, Kusewitt DF, Bedford MT, Aldaz CM: Generation and characterization of mice carrying a conditional allele of the Wwox tumor suppressor gene. PLoS One 2009, 4:e7775.

5. Chen ST, Chuang Jl, Cheng CL, Hsu LJ, Chang NS: Light-induced retinal damage involves tyrosine 33 phosphorylation, mitochondrial and nuclear translocation of WW domain-containing oxidoreductase in vivo. Neuroscience 2005, 130:397-407.

6. Chen ST, Chuang Jl, Wang JP, Tsai MS, Li H, Chang NS: Expression of WW domain-containing oxidoreductase WOX1 in the developing murine nervous system. Neuroscience 2004, 124:831-839.

7. Suzuki H, Katayama K, Takenaka M, Amakasu K, Saito K, Suzuki K: A spontaneous mutation of the Wwox gene and audiogenic seizures in rats with lethal dwarfism and epilepsy. Genes Brain Behav 2009, 8:650-660.
8. Li H, Durbin R: Fast and accurate short read alignment with Burrows-Wheeler transform. Bioinformatics 2009, 25:1754-1760.

9. McKenna A, Hanna M, Banks E, Sivachenko A, Cibulskis K, Kernytsky A, Garimella K, Altshuler D, Gabriel S, Daly M, DePristo MA: The genome analysis toolkit: a MapReduce framework for analyzing next-generation DNA sequencing data. Genome Res 2010, 20:1297-1303.

10. McLaren W, Pritchard B, Rios D, Chen Y, Flicek P, Cunningham F: Deriving the consequences of genomic variants with the Ensembl API and SNP Effect Predictor. Bioinformatics 2010, 26:2069-2070.

11. Szpiech ZA, Xu J, Pemberton TJ, Peng W, Zollner S, Rosenberg NA, Li JZ: Long runs of homozygosity are enriched for deleterious variation. Am J Hum Genet 2013, 93:90-102.

12. Rabbitts $\mathrm{TH}$, Forster $\mathrm{A}$, Larson $\mathrm{R}$, Nathan P: Fusion of the dominant negative transcription regulator CHOP with a novel gene FUS by translocation $\mathrm{t}(12 ; 16)$ in malignant liposarcoma. Nat Genet 1993, 4:175-180.

13. Kwiatkowski TJ Jr, Bosco DA, Leclerc AL, Tamrazian E, Vanderburg CR, Russ C, Davis A, Gilchrist J, Kasarskis EJ, Munsat T, et al: Mutations in the FUS/TLS gene on chromosome 16 cause familial amyotrophic lateral sclerosis. Science 2009, 323:1205-1208.

14. Kratz CP, Niemeyer CM, Zenker M: An unexpected new role of mutant Ras: perturbation of human embryonic development. J Mol Med 2007, 85:227-235.

15. MacArthur DG, Balasubramanian S, Frankish A, Huang N, Morris J, Walter K, Jostins L, Habegger L, Pickrell JK, Montgomery SB, et al: A systematic survey of loss-of-function variants in human protein-coding genes. science 2012, 335:823-828.

16. Chang JY, He RY, Lin HP, Hsu LJ, Lai FJ, Hong Q, Chen SJ, Chang NS: Signaling from membrane receptors to tumor suppressor WW domain-containing oxidoreductase. Exp Biol Med 2010, 235:796-804.

17. Bowes C, Li T, Danciger M, Baxter LC, Applebury ML, Farber DB: Retinal degeneration in the rd mouse is caused by a defect in the beta subunit of rod cGMP-phosphodiesterase. Nature 1990, 347:677-680.

18. Olichon A, Baricault L, Gas N, Guillou E, Valette A, Belenguer P, Lenaers G: Loss of OPA1 perturbates the mitochondrial inner membrane structure and integrity, leading to cytochrome $\mathrm{c}$ release and apoptosis. J Biol Chem 2003, 278:7743-7746.

19. Wang SW, Mu X, Bowers WJ, Kim DS, Plas DJ, Crair MC, Federoff HJ, Gan L, Klein WH: Brn3b/Brn3c double knockout mice reveal an unsuspected role for Brn3c in retinal ganglion cell axon outgrowth. Development 2002, 129:467-477.

20. Ageilan RI, Hassan MQ, de Bruin A, Hagan JP, Volinia S, Palumbo T, Hussain S, Lee SH, Gaur T, Stein GS, et al: The WWOX tumor suppressor is essential for postnatal survival and normal bone metabolism. J Biol Chem 2008, 283:21629-21639.

21. Ageilan RI, Trapasso F, Hussain S, Costinean S, Marshall D, Pekarsky Y, Hagan JP, Zanesi N, Kaou M, Stein GS, et al: Targeted deletion of Wwox reveals a tumor suppressor function. Proc Natl Acad Sci USA 2007, 104:3949-3954.

22. Ageilan Rl, Hagan JP, de Bruin A, Rawahneh M, Salah Z, Gaudio E, Siddiqui $H$, Volinia S, Alder H, Lian JB, et al: Targeted ablation of the WW domain-containing oxidoreductase tumor suppressor leads to impaired steroidogenesis. Endocrinology 2009, 150:1530-1535.

doi:10.1186/1750-1172-9-12

Cite this article as: Abdel-Salam et al:: The supposed tumor suppressor gene WWOX is mutated in an early lethal microcephaly syndrome with epilepsy, growth retardation and retinal degeneration. Orphanet Journal of Rare Diseases 2014 9:12 